\title{
Scl-86, A Marker Antigen for Diffuse Scleroderma
}

\author{
W. J. van Venrooij, S. O. Stapel, H. Houben, W. J. Habets, C. G. M. Kallenberg, E. Penner, and L. B. van de Putte \\ Department of Biochemistry and Department of Rheumatology, University of Nijmegen. The Netherlands; Department of Clinical \\ Immunology, University of Groningen. The Netherlands; and First Department of Gastroenterology and Hepatology,
}

University of Vienna, Austria

\section{Abstract}

More than $\mathbf{3 0 0}$ sera from patients with a connective tissue disease were analyzed with the immunoblotting technique. The presence of autoantibodies against an 86,000-mol wt marker antigen for diffuse scleroderma (Scl-86) was found in 14 out of 33 patients with scleroderma. The presence of anti-Scl-86 antibodies seemed to correlate with the diagnosis of diffuse scleroderma since they were found in 13 out of 22 diffuse scleroderma patients and in only one out of 11 patients with limited scleroderma. All scleroderma sera (33 patients' sera and 13 reference sera) were also tested for the presence of anti-Scl-70 antibodies. It was found that all anti-Scl-70 positive sera $(n=25)$ contained anti-Scl-86 antibody as well, suggesting a relationship between these two antigens. However, the Scl86 antigen was shown to be an extremely insoluble nonchromosomal protein, resistant to boiling in sodium dodecyl sulfate. This contrasts with the Scl-70 antigen, which has been described as a thermolabile, soluble antigen present in the chromatin fraction. Together, our results are consistent with the idea that Scl-70 is a degradation product of Scl-86.

The Scl-86 antigen is present in freshly prepared rabbit thymus, spleen, and liver nuclei as well as in nuclei from various cultured cell lines, but is not detectable in extractable nuclear antigen from rabbit thymus.

In a limited retrospective study, the anti-Scl-86 antibodies were found in two sera from patients with Raynaud's phenomenon before the development of diffuse scleroderma. Therefore, it is possible that screening of patients' serum for this antibody might predict the development of diffuse scleroderma.

\section{Introduction}

Circulating autoantibodies in patients with connective tissue diseases are mostly directed against macromolecular components involved with the protein synthetic machinery, such as DNA, small nuclear RNA-protein particles, nucleolar components, and a variety of nonhistone protein complexes (1). Some of these autoantibodies might also be a marker for specific syndromes. Anti-ribonucleoprotein (RNP)! , anti-Sm-, and anti-La/SS-B antibodies, for instance, are thought to be

Dr. Habets was a recipient of a grant from the "Praeventiefonds," The Hague, The Netherlands.

Address correspondence to Dr. van Venrooij, Department of Biochemistry, Geert Grooteplein 21 Noord, 6525 EZ Nijmegen, The Netherlands.

Received for publication 28 June 1984 and in revised form 14 November 1984.

J. Clin. Invest.

(c) The American Society for Clinical Investigation, Inc.

0021-9738/85/03/1060/08 \$1.00

Volume 75, March 1985, 1053-1060 characteristic for mixed connective tissue disease (MCTD), systemic lupus erythematosus (SLE), and Sjögren's syndrome (SS) (1-3), respectively, and each of these antibodies recognizes specific particles containing small nuclear RNAs and antigenic proteins (4-9). Due to this circumstance, diagnosis has been facilitated by subjecting the sera to specific immunological tests, such as indirect immunofluorescence techniques, immunodiffusion, counterimmunoelectrophoresis, and more recently, immunoprecipitation and immunoblotting (4-9).

Apart from the reported antibodies to nucleolar RNPs and laminar proteins in single scleroderma sera $(10,11)$, three types of autoantibodies have been suggested to be associated specifically with progressive systemic sclerosis: $(a)$ antibody to centromere/kinetochore, reported to be a marker antibody for the Calcinosis, Raynaud's phenomenon, esophageal dysmotility, sclerodactyly, and telangiectasia (CREST) variant $(12,13) ;(b)$ antibody to a basic, labile, chromatine-associated, nonhistone 70,000 -mol wt nuclear protein $(\mathrm{Scl}-70)(14,15)$; and $(c)$ antinucleolar antibody (16), which might be specific for scleroderma or diseases with scleroderma overlap features.

Anti-nucleolar and anti-centromere antibodies can in most cases be visualized by indirect immunofluorescence techniques, using tissue culture cells as substrate (13). Determination of anti-Scl-70 activity is achieved by immunodiffusion against $\mathrm{KCl}$-extracts of rat liver nuclei (14) or freshly prepared rabbit thymus extracts (15).

To find out if the application of the immunoblotting technique could possibly yield more information on the molecular composition of the antigens recognized by scleroderma sera, we subjected various patients' sera, and several Scl-70, and anti-centromere reference sera to this procedure. Our results revealed the presence of autoantibodies against a 86,000mol wt nuclear antigen (Scl-86), which were found almost exclusively in the sera of patients suffering from diffuse scleroderma. Furthermore, these antibodies were rarely found in centromere-staining sera from CREST patients, suggesting that the presence of antibodies to Scl-86 can differentiate between diffuse scleroderma and CREST.

\section{Methods}

Patients. Patient sera were obtained from the Department of Rheumatic Diseases of the University Hospital of Nijmegen and the University

1. Abbreviations used in this paper: ANA, autoantibodies to nuclear antigens (nuclear staining in immunofluorescence); CREST, Calcinosis, Raynaud's phenomenon, esophageal dysmotility, sclerodactyly, and telangiectasia; DNase, deoxyribonuclease; ENA, extractable nuclear antigen; MCTD, mixed connective tissue disease; PAGE, polyacrylamide gel electrophoresis; PMSC, phenylmethylsulphonyl chloride; RNase, ribonuclease; RNP, ribonucleoprotein; RSB, reticulocyte suspension buffer; Scl-70, a basic, labile, chromatine-associated, nonhistone 70,000mol wt nuclear protein; Scl-86, an 86,000-mol wt marker nuclear antigen for diffuse scleroderma; SLE, systemic lupus erythematosus; SS, Sjögren's syndrome. 
Hospital of Groningen, The Netherlands. Most of these sera were selected on the basis of a clinical diagnosis or a positive nuclear staining in immunofluorescence (ANA pattern) using HEp-2 or WISH cells in culture as the substrate. Diagnoses were based on preliminary or definitive criteria as described in the legends of Tables I and II. Scl70 reference sera were obtained from the First Department of Gastroenterology and Hepatology, University of Vienna, Austria, from Dr. E. M. Tan, Scripps Clinic, LaJolla, CA, and from Dr. P. Maddison, Royal National Hospital for Rheumatic Diseases, Bath, England.

Table I. Serological and Clinical Data of 33 Patients with Systemic Sclerosis

\begin{tabular}{|c|c|c|c|c|}
\hline Patient & $\begin{array}{l}\text { Additional } \\
\text { clinical symptoms }\end{array}$ & Scl-70 & ANA & Scl-86 \\
\hline \multicolumn{5}{|c|}{ Patients with diffuse scleroderma } \\
\hline B 02 & RES & + & 1,2 & + \\
\hline B 05 & CREST & + & 1,2 & + \\
\hline В 09 & REST & + & 4 & + \\
\hline B 10 & CREST & + & 1 & + \\
\hline B 11 & RES & - & 2 & - \\
\hline B 19 & n.d. & + & 1,2 & + \\
\hline G 02 & CREST & + & 1 & + \\
\hline H 35 & RST & + & 1 & + \\
\hline I 02 & CRES & - & 3 & - \\
\hline K 02 & REST & - & 2 & - \\
\hline K 13 & CRST & - & 2 & + \\
\hline L 18 & RS & + & 1,2 & + \\
\hline M 02 & CREST & - & 0 & - \\
\hline M 03 & REST & + & 1 & + \\
\hline O 02 & RES & + & 1,2 & + \\
\hline S 11 & CREST & + & 4 & + \\
\hline T 01 & RES & - & 0 & - \\
\hline V 18 & CREST & - & 0 & - \\
\hline W 04 & RES & - & 0 & - \\
\hline W 05 & RES & - & 0 & - \\
\hline W 18 & RES & - & 0 & - \\
\hline $\mathrm{Z} 03$ & RES & + & 1 & + \\
\hline
\end{tabular}

Patients with limited scleroderma*

\begin{tabular}{lllll} 
A 08 & CREST & + & 1 & + \\
B 01 & CREST & - & 3 & - \\
B 15 & RST & - & 3 & - \\
B 30 & RST & - & 1 & - \\
F 01 & REST & - & 4 & - \\
F 09 & CRST & - & 1,3 & - \\
J 04 & CREST & - & 3 & - \\
T 05 & REST & - & 2 & - \\
T 06 & CRES & - & 3 & - \\
V 01 & CREST & - & 0 & - \\
V 24 & CRST & - & 3 & - \\
\hline
\end{tabular}

* Confined to the fingers (sclerodactyly) and face. The medical records of all patients were reviewed by Dr. Houben and diagnosed using the preliminary criteria of Masi et al. (18). Scl70-activity was determined by immunodiffusion (see Methods) without prior knowledge of the immunoblotting data or diagnosis. The ANA patterns (see Methods) distinguished were: 0 , negative fluorescence; 1 , diffusely grainy pattern not involving nucleoli, often with perinucleolar rings; 2 , nucleolar staining; 3 , centromere staining; and 4 , immunofluorescence staining different from 1,2 , or 3 .
Table II. Diagnoses of Patients Correlated with the Presence of Anti-Scl-86 Antibodies

\begin{tabular}{lcc}
\hline Diagnosis & No. of patients & Scl-86 \\
\hline Scleroderma & & \\
PSS-diffuse & 22 & 13 \\
(C)R(E)ST & 11 & 1 \\
Dermato/polymyositis & 12 & 1 \\
MCTD & 42 & 0 \\
SLE & 58 & 2 \\
RA & 133 & 0 \\
SS & 21 & 0 \\
UCTD & 19 & 0 \\
\end{tabular}

All patients were seen at the St. Radboud Hospital in Nijmegen and diagnosed using the following criteria. Mixed connective tissue disease (MCTD) as described by Sharp (27), polymyositis and dermatomyositis as described by Bohan and Peter (28), systemic lupus erythematosus (SLE) following the 1982 revised criteria (29), rheumatoid arthritis (RA) as described by Ropes et al. (30), Sjögren's syndrome (SS) as described by Moutsopoulos (31). Undifferentiated connective tissue disease (UCTD) was used when the patient did not fulfill sufficient criteria for a final diagnosis.

Immunoblotting and immunodiffusion. Preparation of HeLa nuclear antigens, sodium dodecyl sulfate polyacrylamide gel electrophoresis (SDS-PAGE), protein electroblot transfer to nitrocellulose paper, and detection of antigens on the blot were performed as described earlier $(9,17,18)$.

The immunodiffusion test for measuring anti-Scl-70 activity was performed using extractable nuclear antigen (ENA) (lyophilized extract from Pel-Freeze Biologicals, Rogers, AR) in a very concentrated solution $(60-80 \mathrm{mg} / \mathrm{ml})$. Wells, 4-mm diam, for serum and antigen solutions, were $\sim 2 \mathrm{~mm}$ apart.

HeLa cell fractionation. Fractionation of HeLa S3 cells was performed essentially as previously described (17), with some modifications. $1 \times 10^{8}$ cells were harvested on frozen NKM solution $(130 \mathrm{mM} \mathrm{NaCl}$, $5 \mathrm{mM} \mathrm{KCl}$, and $1.5 \mathrm{mM} \mathrm{MgCl}$ ), pelleted by centrifugation ( $5 \mathrm{~min}$ at $800 \mathrm{~g}$ ), and washed three times with NKM solution. The cell pellet was resuspended in cold reticulocyte suspension buffer (RSB) $(10 \mathrm{mM}$ Tris, $\mathrm{pH} 7.4 ; 1.5 \mathrm{mM} \mathrm{MgCl} 2 ; 10 \mathrm{mM} \mathrm{NaCl} ; 0.5 \mathrm{mM}$ phenylmethylsulphonyl chloride-PMSC) and after addition of a $0.5 \%$ Na-deoxycholate-1\% Tween 40 (Atlas Powder Co., Wilmington, DE) mixture homogenized by five strokes of a motor-driven Teflon pestle in a Potter-Elvehjem type tissue homogenizer (Kontes Co., Vineland, NJ). The nuclei were pelleted, and the supernatant, containing the DOC/ Tween soluble proteins, was removed. This latter fraction is further referred to as cytoplasmic fraction. The nuclei were washed three times with RSB, and resuspended in $\mathrm{HRSB}(110 \mathrm{mM} \mathrm{NaCl}, 10 \mathrm{mM}$ Tris, pH 7.4, $1.5 \mathrm{mM} \mathrm{MgCl}$, and $0.5 \mathrm{mM}$ PMSC) and incubated for 15 min at $20^{\circ} \mathrm{C}$ with deoxyribonuclease (DNase) I $(500 \mu \mathrm{g} / \mathrm{ml})$. After centrifugation $(10 \mathrm{~min}$ at $800 \mathrm{~g}$ ) and removal of the supernatant (DNase-fraction), the DNA-depleted nuclei were washed and resuspended again in HRSB and treated with ribonuclease (RNase) A (100 $\mu \mathrm{g} / \mathrm{ml}$ ) for $10 \mathrm{~min}$ at $37^{\circ} \mathrm{C}$. After centrifugation, removal of the supernatant (RNase-fraction), and washing with RSB, the nucleic aciddepleted nuclei were resuspended in $0.4 \mathrm{M}\left(\mathrm{NH}_{4}\right)_{2} \mathrm{SO}_{4} 30 \mathrm{mM}$ Tris (pH 7.4), $0.5 \mathrm{mM} \mathrm{PMSC}$, and again pelleted by centrifugation ( $5 \mathrm{~min}$ at $800 \mathrm{~g}$ ). The supernatant (high-salt fraction) was saved, and the pellet contained the insoluble nuclear proteins, mostly referred to as the nuclear matrix fraction. The supernatants from the cytoplasmic fraction and the DNase-, the RNase-, and high-salt-treatments were freed from nuclear remnants by an additional centrifugation ( $30 \mathrm{~min}$ at $8,400 \mathrm{~g}$ ), dialyzed against $0.1 \% \mathrm{NH}_{4} \mathrm{HCO}_{3}$, and lyophilized before SDS-PAGE. 


\section{Results}

Patients' sera. In our sera stock from about 300 patients, there were 22 sera from patients with a fully developed diffuse scleroderma. This clinical diagnosis was reached using the preliminary criteria of Masi et al. (19). Most patients (16 out of 22) had a positive ANA showing a diffusely grainy nucleoplasmic staining $(n=10)$, in five cases also involving the nucleoli. In six cases the ANA was negative, and in three cases a nucleolar staining was predominant (see Table I). Immunodiffusion analysis using a freshly prepared extract of rabbit thymus powder revealed the presence of anti-Scl-70 activity in 12 of these sera.

From hospitals in Vienna, Austria; LaJolla, CA; and London, England, we obtained 13 other sera with anti-Scl-70 activity. All these sera, except one with unknown diagnosis, were from patients with diffuse scleroderma, and immunofluorescence on cultured cells, in most cases, showed the typical grainy nucleoplasmic staining shown in Fig. 1.

For retrospective analysis, a third group of sera was obtained from patients suffering from Raynaud's phenomenon, in the early 1970's when they first entered the hospital. Serum from these patients was collected in 1978, 1980, and 1982. 6 out of 18 patients developed scleroderma in the course of 5-10 yr.

The control group of sera consisted of $>230$ sera from patients suffering from all types of other connective tissue diseases, including 11 patients with the $(C) R(E) S T$ variant of scleroderma (see Table II). Furthermore, 54 sera from healthy individuals were used as a control.

Immunoblotting of patients sera. Immunoblots were used to detect polypeptides carrying determinants recognized by antibodies present in the sera described above. When total nuclear protein from purified HeLa cell nuclei (see Methods) was used as the antigen source, most sera were found to recognize one or more polypeptides on the blot. After screening several hundred sera in this way, we could establish that several more-or-less standard blot profiles could be recognized. For example, anti-RNP sera (mostly from MCTD patients) recognize in most cases a 70,000 and/or a 31,000-mol wt polypeptide (the A protein [5]) and/or a 19,000-mol wt polypeptide (the $C$ protein [5]) (Fig. 2, lanes 1 and 3). There is, however, a considerable variation in the blot patterns of these types of sera (18), even among sera precipitating only the complex of U-1-small nuclear RNA with proteins (U-1 snRNP) particle (Habets et al., manuscript submitted for publication). Anti-Sm sera always recognize a protein doublet of 25,000 mol wt (the B-B' doublet [5]) and a polypeptide of 13,000 mol wt [the D protein (5); see also Fig. 2, lanes 2 and 3]. Anti-SSB (anti-La) sera always recognize a 50,000-mol wt antigen ([9]; see also Fig. 2, lane 4).

In the routine screening of sera from scleroderma patients, we observed that a number of patients with clinically defined CREST syndrome recognized a 17,000-mol wt antigen (Fig. 2, lane 5; and S. O. Stapel, manuscript in preparation), while patients with the diagnosis diffuse scleroderma showed activity against an 86,000-mol wt protein (Fig. 2, lane 6). From 22 patients with diffuse scleroderma, 13 sera $(60 \%)$ contained antibody against an 86,000-mol wt protein (Table I, Fig. 3). Only in four other patients (one polymyositis, one CREST, and two SLE) out of a few hundred, the 86,000 -mol wt band was found in the blot pattern, supporting the idea that this antigen is specifically recognized by antibodies produced in diffuse scleroderma patients (Table II). For convenience, we will refer to this antigen as Scl-86.

It has been described that Scl-70 could be a marker antigen for scleroderma (14), although anti-Scl-70 antibodies were detected in only a low percentage of the patients $(15,16)$. Interestingly, no 70,000-mol wt protein was detected by immunoblotting, although 12 patients showed anti-Scl- -70 activity in the immunodiffusion assay. Therefore, we collected other anti-Scl-70 positive sera, 10 from the First Department of Gastroenterology and Hepatology in Vienna, Austria, one from the Scripps clinic in LaJolla, CA, and two from the Royal National Hospital in Bath, England. All 13 sera showed the presence of antibodies against the Scl-86 antigen (three of them are shown in Fig. 3); none had activity against proteins in the 70,000-mol wt range.

In vitro degradation of the Scl-86 antigen. The results

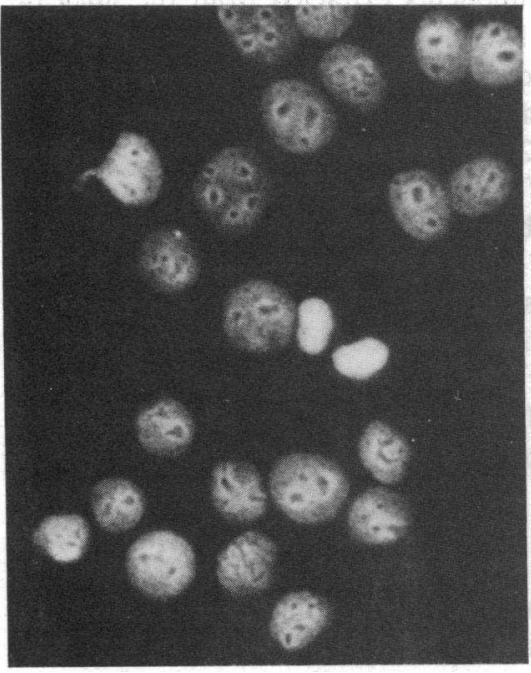

A

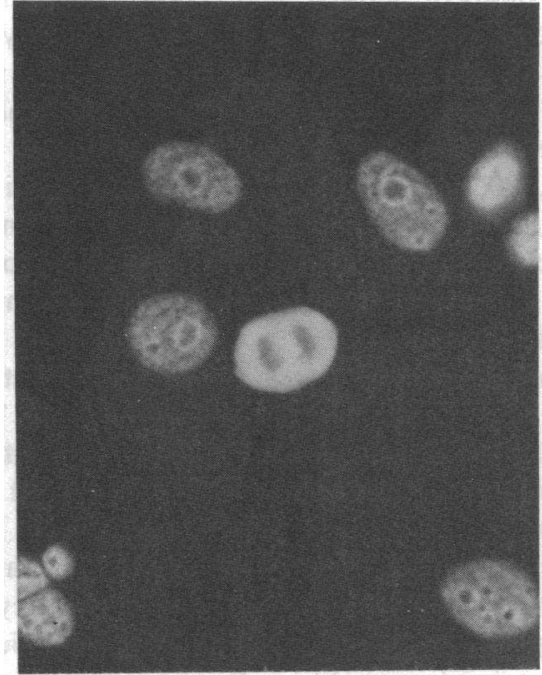

B

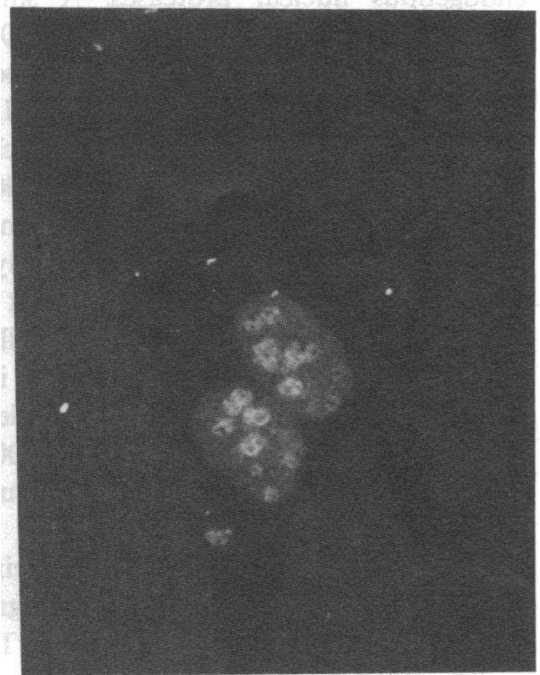

C

Figure 1. Patterns of nucleoplasmic staining of a diffuse scleroderma serum (patient G2) on various cell lines. $(A)$ HEp-2, a human epithelial cell line from larynx; $(B)$ WISH, a human amnion tissue epithelial cell line; $(C)$ lens cells, an epithelial line from calf eye lens tissue (26). 

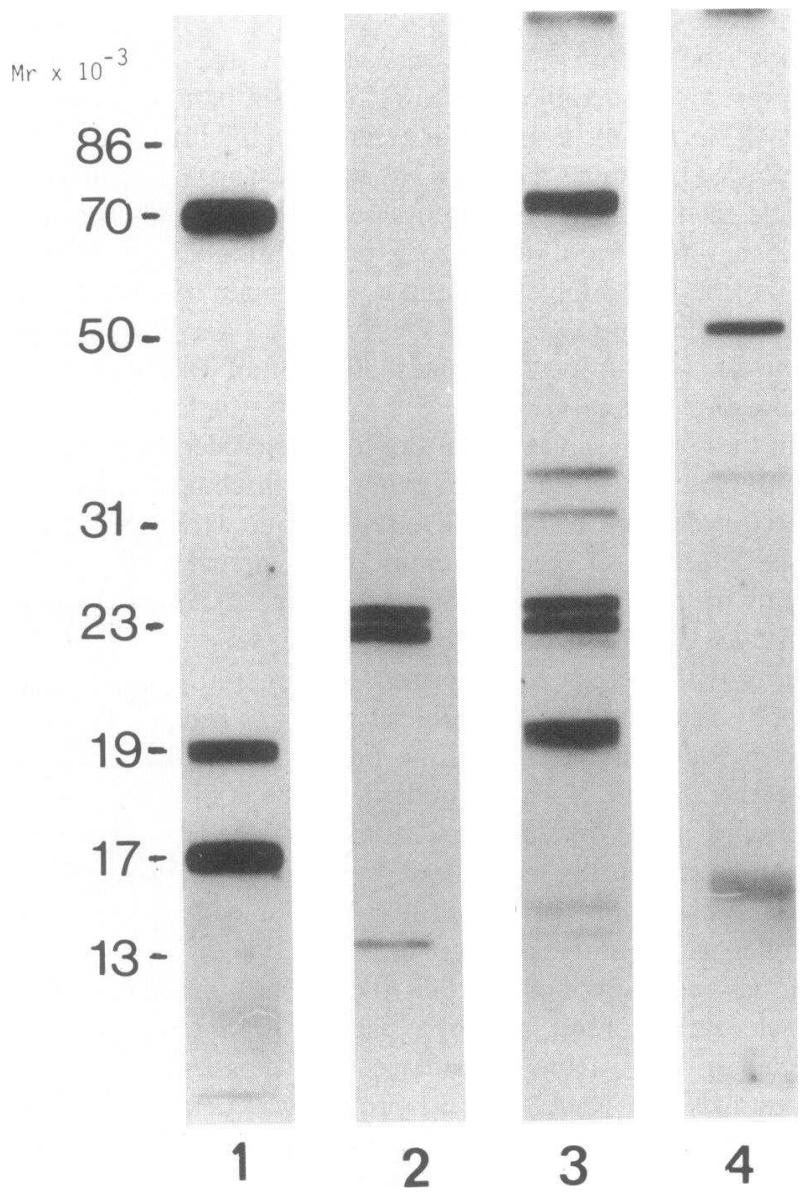

3

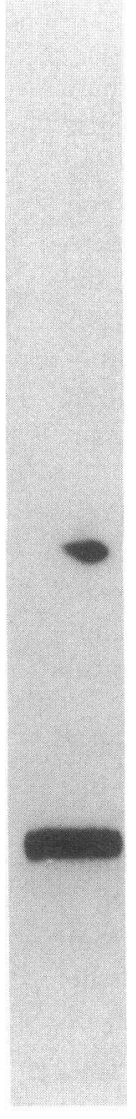

5

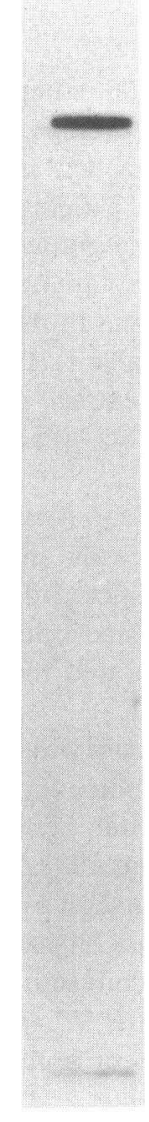

6
Figure 2. Immunoblot patterns of various types of patients sera. HeLa cell total nuclear protein fraction was isolated as described in Methods and separated into individual polypeptide constituents by SDS-PAGE. Subsequently, the gel was blotted electrophoretically onto nitrocellulose and was probed with various patients sera (lanes 1-6). Immunoreactive species were detected using ${ }^{125}$ I-labeled protein A. For further details see references 9 and 18 . Lane 1, anti-RNP serum from MCTD patient (H 13); lane 2, anti-Sm serum from SLE patient (H 11); lane 3, anti-Sm and anti-RNP antibody containing serum from SLE patient (B 16); lane 4, anti-SS-B serum from patient with Sjögren's syndrome and Sicca complex (W 10); lane 5, anti-centromere/kinetochore antibody containing serum from CREST patient (J 4); and lane 6, anti-Scl-86 antibody containing serum from diffuse scleroderma patient (G 2). described above indicate that the Scl-70 antigen might be a (proteolytic) degradation product from the Scl-86 antigen found by immunoblotting. Therefore, the possibility that these antigens were related to each other was examined.

A freshly prepared HeLa cell nuclear extract (see Methods) was incubated at various temperatures and for different periods of time to allow degradation of the antigens in vitro by endogenous nuclear proteases. A similar protocol showed earlier that the SS-B antigen of $50,000 \mathrm{~mol} \mathrm{wt}$ is degraded rapidly to lower molecular weight products still carrying the SS-B specific determinants (9). Indeed, the Scl-86 antigen is degraded during incubation of the nuclear extract, and intermediate degradation products of $82,000,76,000,72,000$, and $64,000 \mathrm{~mol} \mathrm{wt}$ appear while two smaller intermediates of 49,000 and 47,000 mol wt, respectively, accumulate (Fig. 4). The 76,000 and 64,000-mol wt, but also the 49,000 and 47,000-mol wt intermediates are still present after longer incubation times, suggesting that these intermediates are more stable degradation products. It is possible that the accumulating species of 64,000 or 49,000 and 47,000 mol wt are identical with the Scl-70 antigen isolated by Douvas et al. (14).

The amount of antigen that can be immunoblotted in lanes 2, 3, and 4 (particularly the proteins of molecular weight 47,000 and 49,000 ) seem to be much greater in concentration than the $86,000-\mathrm{mol}$ wt protein band. This is probably caused by the well known phenomenon that low molecular weight proteins are more efficiently transferred to nitrocellulose than high molecular weight proteins (20).

Detection of Scl-86 in HeLa cell fractions. For the subcellular localization of Scl-86 antigen, a cell fractionation procedure was used (see Methods) that resulted in $(a)$ a cytoplasmic fraction containing also the readily soluble components of the nucleoplasm; $(b)$ a DNase fraction containing nuclear components released by extensive DNase I treatment of the nuclei; (c) an RNase fraction containing components released from the nuclei by extensive RNase A treatment; $(d)$ a high salt fraction containing components extracted from the nuclease treated nuclei by $0.4 \mathrm{M}\left(\mathrm{NH}_{4}\right)_{2} \mathrm{SO}_{4}$; and $(e)$ the resulting insoluble nuclear fraction predominantly composed of a complex mixture of nonhistone proteins and generally referred to as nuclear matrix $(17,21)$.

For the detection of antigens in these soluble and insoluble fractions, the immunoblotting technique is very well suited. After solubilization of the fractions in 2\% SDS containing sample buffer, antigens can be separated according to their molecular weight by PAGE, blotted onto nitrocellulose, and used as a substrate for the immunoreaction. The results are shown in Fig. 5. The fractionation procedure used seems to succeed in separating groups of proteins belonging to physiologically different cell compartments (see Coomassie Blue stained lanes, Fig. $5 \mathrm{~A}$ ). Using similar gels for the immunoblotting, we found that, for example, the SS-B antigen is primarily localized in the cytoplasmic fraction (Fig. $5 B$, lane 2). This confirms our earlier observation that $>80 \%$ of the cellular SSB antigen is present in a soluble or easily extractable form (9). Part of the SS-B antigen, however, is found in the nuclear matrix fraction (Fig. $5 \mathrm{~B}$, lane 6). Incubation of a similar blot with an anti-Scl-86 serum showed that this antigen can be 


\section{$\operatorname{Mr} \times 10^{-3}$}

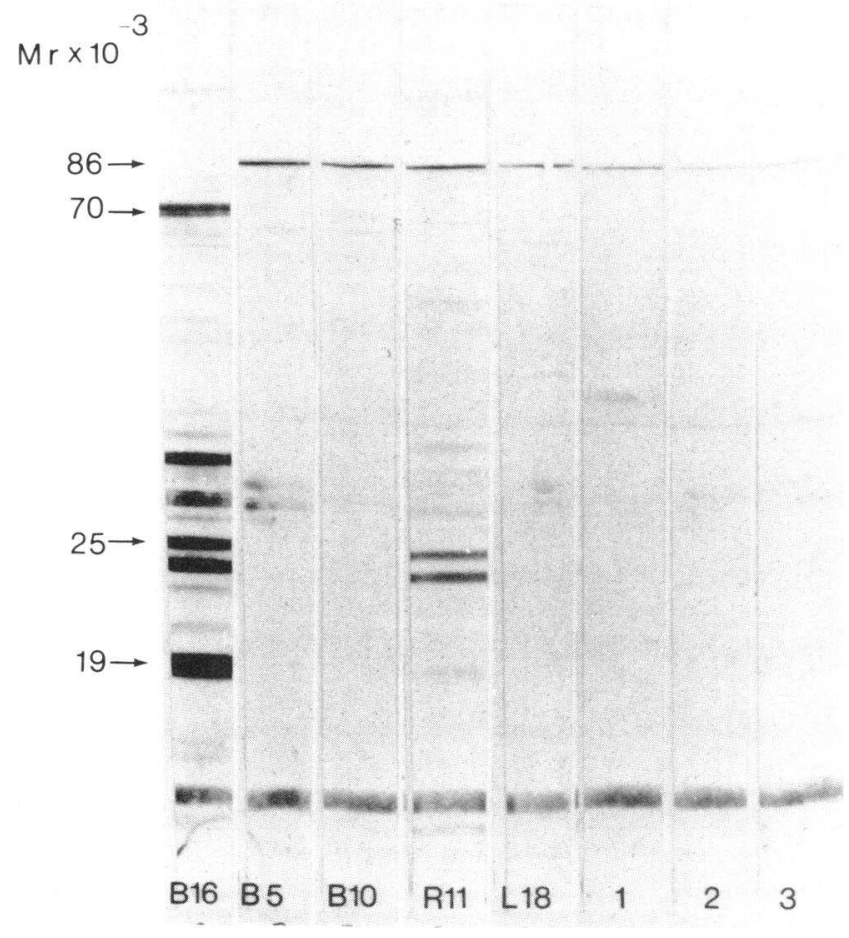

Figure 3. Immunoblot patterns of anti-Scl-86 and anti-Scl- 70 sera. Immunoblotting was performed as described in the legend of Fig. 2. The blot strips were incubated for $1 \mathrm{~h}$ with horseradish peroxidase conjugated anti-human IgG, and peroxidase activity was detected by incubating the washed blots in phosphate buffered saline $(10 \mathrm{mM}$ phosphate buffer in $0.9 \% \mathrm{NaCl}, \mathrm{pH} 7.5)$ containing 4-chloro-1naphtol $(0.5 \mathrm{mg} / \mathrm{ml})$ and $\mathrm{H}_{2} \mathrm{O}_{2}(0.06 \%)$. B 16 , reference serum containing anti-Sm and anti-RNP antibody; B 5, B 10, B 11, R 11, and L 18, anti-Scl-86 positive sera; 1,2 , and 3, anti-Scl-70 reference sera.

detected only in the water-insoluble nuclear matrix fraction (Fig. 5 B, lane 6). Such results were consistently obtained using various anti-Scl-86 sera.

Presence of Scl-86 antigen in nuclei from rabbit tissues. To determine whether the Scl-86 antigen was also present in nuclei from other types of cells, we prepared nuclei from various cultured cell lines and from rabbit tissues like thymus, spleen, and liver (18). Total protein extracts from these nuclei, prepared as described in Methods, were blotted and the blots were incubated with Scl-86 positive serum G 2. In all extracts, the Scl-86 polypeptide was the predominant antigen recognized by the patients' autoantibodies (not shown).

We also tested whether Scl-86 was present in the ENA preparation made from commercial rabbit thymus powder. When the ENA was prepared according to the procedure described by Kurata and Tan (22), no Scl-86 antigen could be detected on the blots (data not shown). The same result was obtained when protease inhibitors were included in the extraction buffer, corroborating the insoluble character of this particular antigen. Moreover, also after sonication $(14,23)$, the ENA extract did not contain detectable amounts of the Scl-86 antigen (data not shown).

Possible prognostic value of anti-Scl-86 antibodies. It has been described that anti-centromere/kinetochore antibodies

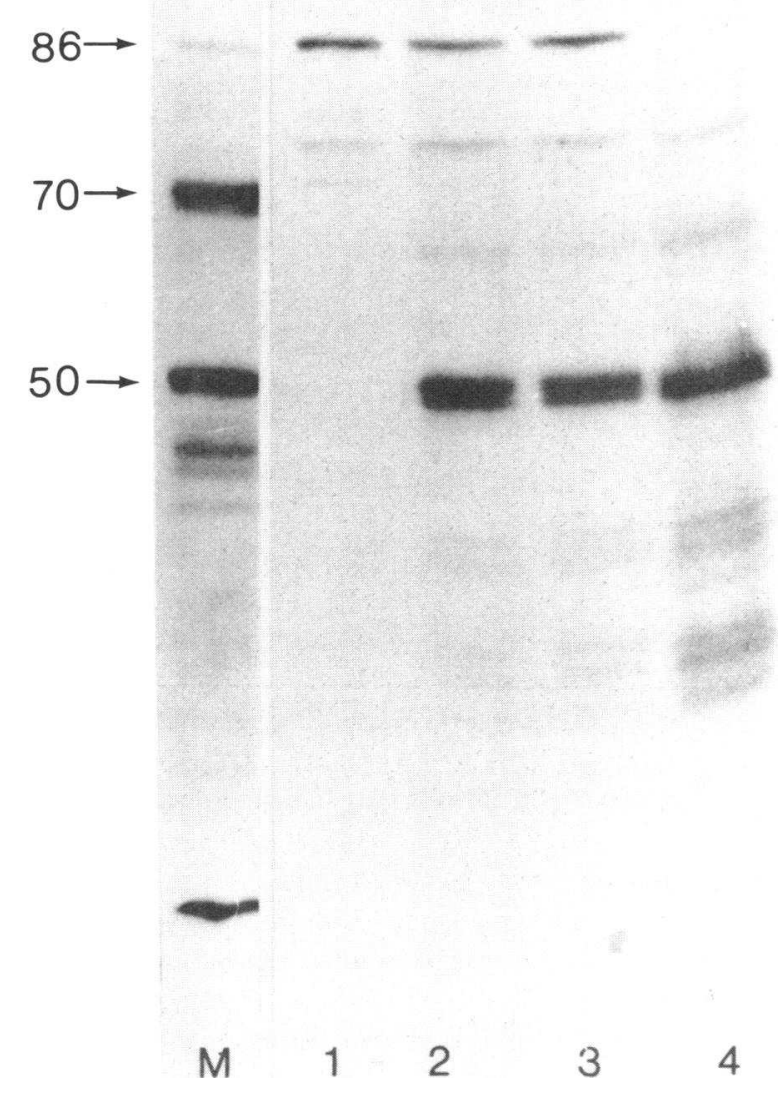

Figure 4. In vitro degradation of the Scl-86 antigen. Total HeLa cell nuclear protein fraction was prepared as described in Methods using $0.5 \mathrm{mM}$ PMSC as an inhibitor of proteolysis. Incubation was performed at $37^{\circ} \mathrm{C}$ and aliquots were removed after 1,2 , and $16 \mathrm{~h}$, solubilized in $2 \%$ SDS containing sample buffer, and analyzed by immunoblotting (via a 10\% polyacrylamide gel) using serum G 2 . Immunoreactive species were detected using ${ }^{125} \mathrm{I}$-labeled protein A. $M$, marker antigens detected on the blot using serum W 10 (anti-SSB recognizing the 50,000-mol wt antigen), B 16 (recognizing the 70,000-mol wt antigen), and G 2 (anti-Scl-86). 1, antigens recognized by serum $G 2$ in freshly prepared nuclear protein fraction; 2,3 , and 4 , antigens recognized by serum $\mathrm{G} 2$ in total nuclear protein fraction incubated at $37^{\circ} \mathrm{C}$ for 1,2 , and $16 \mathrm{~h}$, respectively.

can predate the appearance of a clinical syndrome of CREST (24). Similarly it was found that in 1 of 10 patients with Raynaud's phenomenon without progressive systemic sclerosis, anti-Scl-70 antibodies could be detected (15). It would be interesting and important to know whether the presence of anti-Scl-86 antibodies could also predict the fact that patients are developing the diffuse form of scleroderma. We report the preliminary finding that indeed, this might be the case.

In a retrospective study we analyzed 18 sera from Raynaud's patients that were collected in 1978, 1980, and 1982 (25). The immunoblotting revealed that five of these patients had antibody against the Scl-86 antigen. In 1978, three of them could already be diagnosed as scleroderma patients. However, one patient (Po; in 1978, Raynaud's phenomenon and sclerodactyly were the only signs of a possibly developing scleroderma) had strong anti-Scl-86 activity in 1978, 1980, and 1982. In 1982 this 


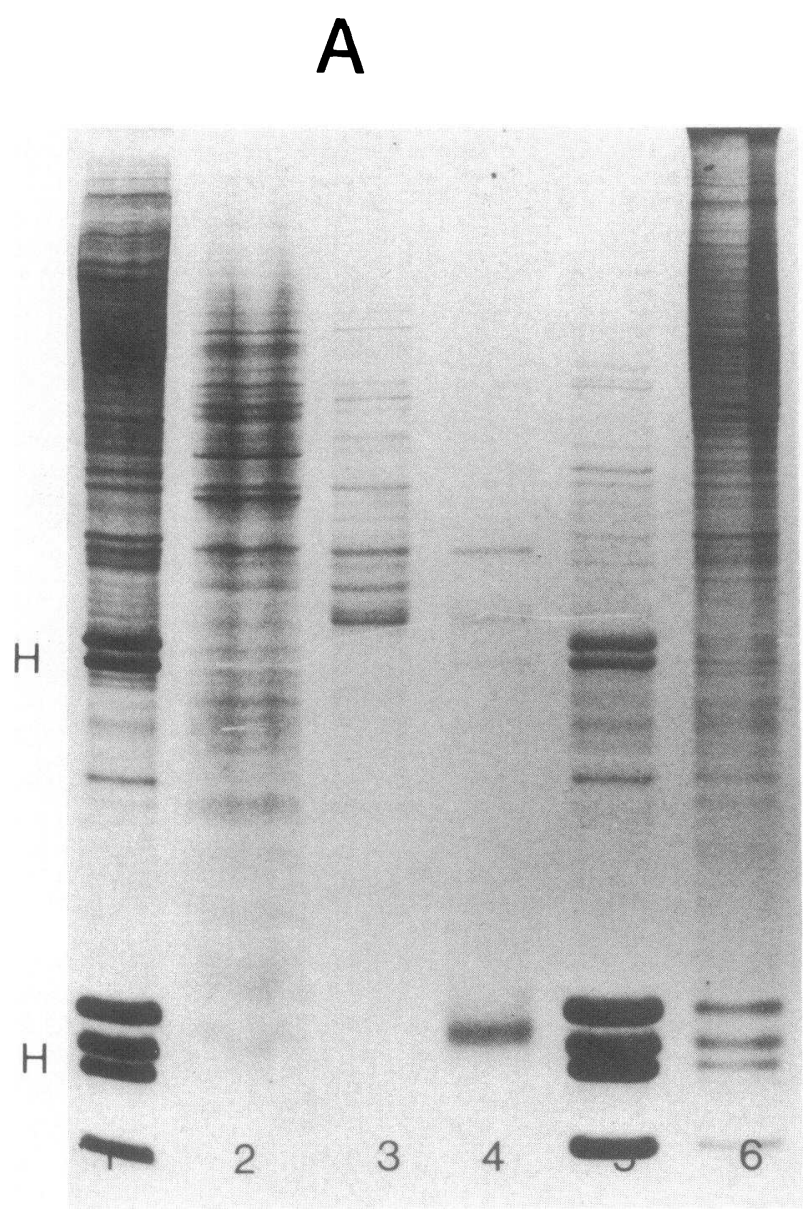

Figure 5. Detection of SS-B and Scl-86 antigens in different cell fractions by immunoblotting. Cell fractions were prepared as described in Methods and the proteins were separated on 15\% SDSpolyacrylamide gels. $(A)$ One gel was stained with Coomassie Blue; $(B)$ two other gels were used for immunoblotting using serum W 10 (anti-SS-B) and G 2 (anti-Scl-86), respectively. The two autoradio-

patient could definitively be diagnosed as having diffuse scleroderma, using the criteria of Masi et al. (19). Another patient in this group (patient Fa) had sclerodactyly and Raynaud in 1978. In 1982 she developed calcinosis as well. The serum taken from this patient in 1978, 1980, and 1982 contained anti-Scl-86 antibodies. Follow-up studies will be necessary to determine whether the use of the blotting technique and the detection of anti-Scl-86 activity might have prognostic value in the diagnosis of diffuse scleroderma.

\section{Discussion}

This study is part of a research project in which $>400$ patients suffering from various types of connective tissue diseases are regularly screened for their profile of circulating autoantibodies. These profiles are measured using various techniques such as counterimmunoelectrophoresis, immunofluorescence, and immunoblotting $(9,18)$. The latter technique has several advantages because it is very sensitive and reproducible and can be used for the screening of large groups of patients' sera. Moreover, due to the SDS-PAGE procedure preceeding the blotting, the technique allows an easy distinction between different groups of specific antibody in one serum. Most important,

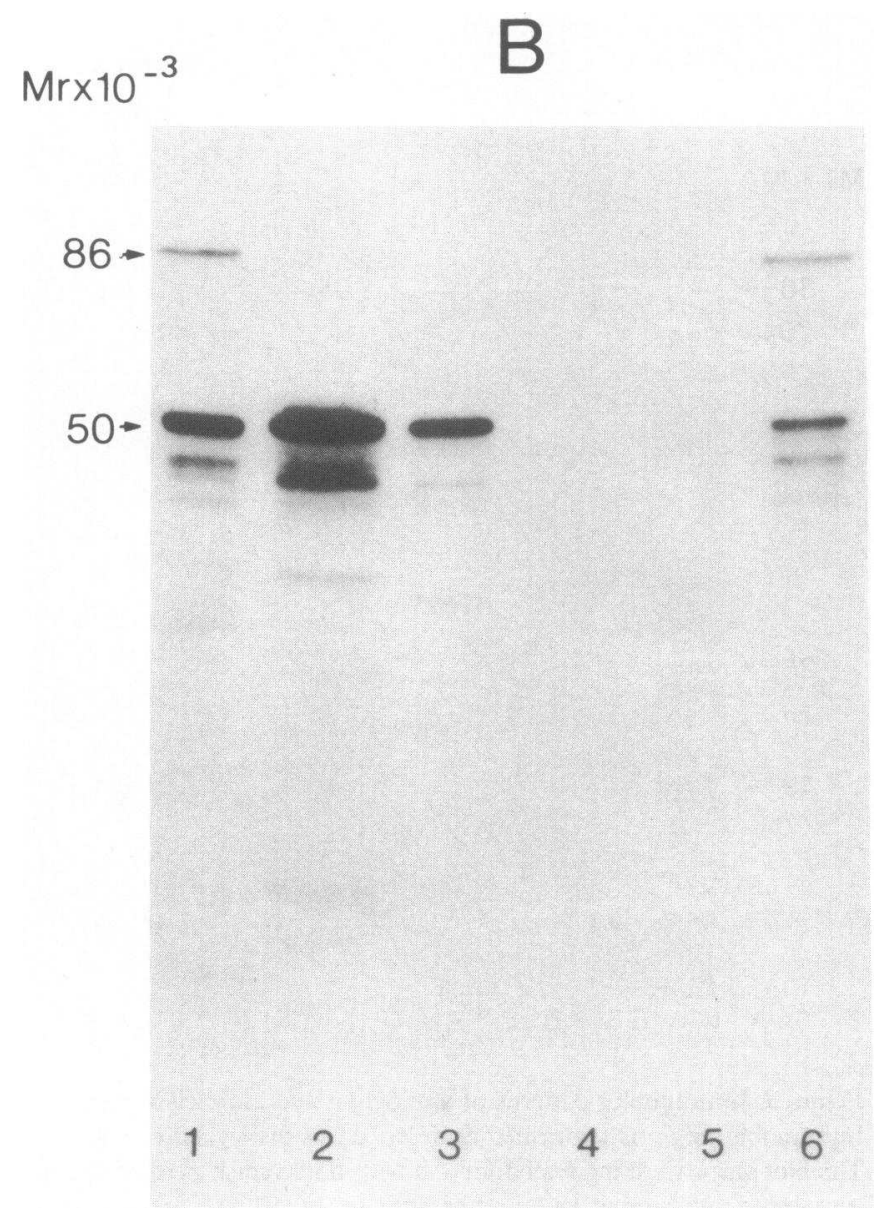

grams obtained with the two individual sera are depicted here in one figure. $\mathrm{H}$, histones; lane 1 , total nuclear protein fraction; lane 2 , cytoplasmic fraction; lane 3, DNase fraction; lane 4, RNase fraction; lane 5, high salt fraction; and lane 6 , insoluble nuclear matrix fraction. For details see the text.

however, is the fact that not only the soluble but also the insoluble antigens can be detected.

The results described in this paper can be summarized in three parts. First, within the group of 33 scleroderma patients tested, 14 patients had antibodies against an 86,000-mol wt nuclear protein (Scl-86). Antibodies against this antigen were detected in only three out of $>250$ patients with another defined connective tissue disease, and not at all in 54 healthy control sera. The presence of anti-Scl-86 antibodies seems to discriminate between the diffuse form of scleroderma and the CREST variant since it is primarily found in patients with the diffuse form of scleroderma (13 out of 22). Therefore, Scl-86 might be considered as a marker antigen for diffuse scleroderma.

Second, the Scl-86 antigen is a very insoluble antigen since it is found only in the so-called nuclear matrix fraction (Fig. $5 \mathrm{~B}$ ). It is not detected in the high salt fraction, which contains most of the chromatin material. The 86,000 -mol wt antigen is present in a variety of cells including rabbit thymus, spleen, and liver. It is not present in detectable amounts in ENA prepared from rabbit thymus.

Third, it is possible that the occurrence of anti-Scl-86 antibodies is an early sign of the development of a full-blown diffuse scleroderma. 
Our main conclusion is that antibody against Scl-86 seems to be characteristic for diffuse scleroderma (Table II). For example, we could detect it in only one out of eleven (C)R(E)ST patients, and even this patient has clinical signs indicating that he possibly is developing diffuse scleroderma. It was described earlier that antibody against Scl-70 seems to be characteristic for progressive systemic sclerosis (15). Indeed, all but one of the anti-Scl-86 antibody-containing sera also show anti-Scl-70 activity (Table I), pointing to the possibility that sera of patients with diffuse scleroderma contain a tandem antibody, one to Scl-70 and the other to Scl-86. Another, in our view more likely, possibility is that both antigens are recognized by the same antibody, i.e., that both antigens have an extremely close chemical relationship. Scl-70 thus could be a degradation product of Scl-86, as suggested by the experiment shown in Fig. 4. In our view, it seems quite possible that the undegraded antigen, Scl-86, a stable and rather insoluble protein with an almost neutral isoelectric point (as judged by 2D-gel electrophoresis, data not shown), after some proteolytic modification, can be transformed into a more basic and labile antigen of lower molecular weight that is also more soluble. However, further study is needed to establish the precise relationship between these two antigens.

Another question is why the Scl-70 antigen cannot be detected in ENA by immunoblotting, since precipitating systems in agarose double diffusion assays usually show up nicely on blots (compare the Sm/RNP system). For the detection of Scl70 in immunodiffusion assays, one generally needs a 5-10 times more concentrated ENA preparation than necessary for the detection of, for example, anti-RNP or anti-Sm. This indicates that the Scl-70 concentration in ENA is rather low. It is possible that the limited amount of protein that can be loaded onto an SDS gel and can be transferred to nitrocellulose does not contain enough Scl-70 antigen for its detection by immunoblotting. Furthermore, part of the antigenic determinants on the Scl-70 antigen might be denatured by the SDSPAGE procedure, further decreasing the detectability of this antigen.

An interesting observation is that anti-Scl-86 antibodies might predict that the patient is developing the diffuse form of scleroderma. It has been reported earlier that anti-Scl-70 antibodies might also have such a prognostic value (15). Follow-up studies will give more definite answers as to whether a more sensitive detection of antibodies against distinct nuclear antigens, such as Scl-86, will have predicting values for diagnosis.

\section{Acknowledgments}

We thank A. A. Groeneveld for performing the immunofluorescence, and Mrs. E. Hitchman for the immunodiffusion experiments. We are grateful to Dr. P. Maddison (Royal National Hospital for Rheumatic Diseases, Bath, England) and Dr. E. M. Tan (Scripps Clinic, LaJolla, CA) for sending us Scl-70 positive reference sera.

This work was supported in part by grants from the Netherlands League against Rheumatism.

\section{References}

1. Tan, E. M. 1982. Autoantibodies to nuclear antigens (ANA): their immunobiology and medicine. Adv. Immunol. 33:167-240.

2. Sharp, G. C., W. S. Irving, C. M. May, H. R. Holman, and F. C. McDuffie. 1976. Association of antibodies to RNP and Sm antigens with mixed connective tissue disease, systemic lupus erythematosus and other rheumatic diseases. N. Engl. J. Med. 295:11491154.

3. Nakamura, R. M., C. L. Peebles, and E. M. Tan. 1978. Microhemagglutination test for detection of antibodies to nuclear $\mathrm{Sm}$ and ribonucleoprotein antigens in systemic lupus erythematosus and related diseases. J. Clin. Pathol. (Lond.). 70:800-807.

4. Akizuki, M., R. Powers, Jr., and H. R. Holman. 1977. A soluble acidic protein of the cell nucleus which reacts with serum from patients with systemic lupus eruythematosus and Sjogren's syndrome. J. Clin. Invest. 59:264-271.

5. Lerner, M. R., and J. A. Steitz. 1979. Antibodies to small nuclear RNAs complexed with proteins are produced by patients with systemic lupus erythematosus. Proc. Natl. Acad. Sci. USA. 76:54955499.

6. Takano, M., P. F. Agris, and G. C. Sharp. 1980. Purification and biochemical characterization of nuclear ribonucleoprotein antigen using purified antibody from serum of a patient with mixed connective tissue disease. J. Clin. Invest. 65:1449-1456.

7. Matter, L., K. Schopfer, J. A. Wilhelm, T. Nijffenegger, R. F. Parisot, and E. M. de Robertis. 1982. Molecular characterization of ribonucleoprotein antigens bound by antinuclear antibodies. Arthritis Rheum. 25:1278-1289.

8. Zieve, G., and F. Salomon. 1982. Proteins specifically associated with the microtubules of the mammalian mitotic spindle. Cell. 28: 233-237.

9. Habets, W. J., J. H. den Brok, A. M. Th. Boerbooms, L. B. A. van de Putte, and W. J. van Venrooij. 1983. Characterization of the SS-B (La) antigen in adenovirus infected and uninfected HeLa cells. EMBO J. 2:1625-1631.

10. Reddy, R., E. M. Tan, D. Henning, K. Nohga, and H. Busch. 1983. Detection of a nucleolar 7-2 ribonucleoprotein with autoantibodies from patients with scleroderma. J. Biol. Chem. 258:1383-1386.

11. McKeon, F. D., D. L. Tuffanelli, K. Fuhuyama, and M. W. Kirscher. 1983. Autoimmune response directed against conserved determinants of nuclear envelope proteins in a patient with linear scleroderma. Proc. Natl. Acad. Sci. USA. 80:4374-4378.

12. Steen, V. D., T. A. Medsger, Jr., G. Ziegler, and G. D. Rodnan. 1980. Clinical comparison of two variants of progressive systemic sclerosis: diffuse scleroderma and CREST syndrome. Arthritis Rheum. 23:752(a). (Abstr.).

13. Moroi, Y., C. Peebles, M. J. Fritzler, J. Steigerwald, and E. M. Tan. 1980. Autoantibody to centromere (kinetochore) in scleroderma sera. Proc. Natl. Acad. Sci. USA. 77:1627-1631.

14. Douvas, A. S., M. Achten, and E. M. Tan. 1979. Identification of a nuclear protein (Scl-70) as a unique target of human antinuclear antibodies in scleroderma. J. Biol. Chem. 254:10514-10522.

15. Tan, E. M., G. P. Rodnan, I. Garcia, Y. Moroi, M. J. Fritzler, and C. Peebles. 1980. Diversity of antinuclear antibodies in progressive systemic sclerosis. Arthritis Rheum. 23:617-625.

16. Bernstein, R. M., J. C. Steigerwald, and E. M. Tan. 1982. Association of antinuclear and antinucleolar antibodies in progressive systemic sclerosis. Clin. Exp. Immunol. 48:43-51.

17. van Eekelen, C. A. G., M. H. L. Salden, W. J. A. Habets, L. B. A. van de Putte, and W. J. van Venrooij. 1982. On the existence of an internal nuclear protein structure in HeLa cells. Exp. Cell Res. 141:181-190.

18. Habets, W. J. A., D. J. de Rooij, M. H. Salden, A. P. Verhagen, C. A. van Eekelen, L. B. van de Putte, and W. J. van Venrooij. 1983b. Antibodies against distinct nuclear matrix proteins are characteristic for mixed connective tissue disease. Clin. Exp. Immunol. 54:265-276.

19. Masi, A. T., and G. F. Rodnan. 1981. Preliminary criteria for the classification of systemic sclerosis (scleroderma). Bull. Rheum. Dis. 31:1-6.

20. Gershoni, J. M., and G. E. Palade. 1983. Protein blotting: principles and applications. Anal. Biochem. 131:1-15.

21. Agutter, P. S., and J. C. W. Richardson. 1980. Nuclear nonchromatin proteinaceous structures. J. Cell. Sci. 44:395-435. 
22. Kurata, N., and E. M. Tan. 1976. Identification of antibodies to nuclear acidic antigens by counterimmuno-electrophoresis. Arthritis Rheum. 19:574-582.

23. Billings, P. B., and S. O. Hoch. 1983. Isolation of intact Sm/ RNP antigens from rabbit thymus. J. Immunol. 131:347-351.

24. Fritzler, M. J., T. D. Kinsella, and E. Garbutt. 1980. The CREST syndrome: a distinct serological entity with anticentromeric antibodies. Am. J. Med. 69:520-528.

25. Kallenberg, G. C. M., A. A. Wouda, and T. H. The. 1980. Clinical and Immunological findings in patients presenting with Raynaud's phenomenon. Am. J. Med. 69:675-680.

26. van Venrooij, W. J., A. A. Groeneveld, and H. Bloemendal. 1974. Cultured calf lens epithelium. Exp. Eye Res. 18:517-526.
27. Sharp, C. G., 1977. Mixed connective tissue disease. In Arthritis and Allied Conditions. D. J. McCarty, editor. Lea \& Febiger, Philadelphia, PA. Ninth ed. 737.

28. Bohan, A., and J. B. Peter. 1975. Polymyositis and dermatomyositis. N. Engl. J. Med. 292:334, 403.

29. Tan, E. M., A. S. Cohen, and J. F. Fries. 1982. The 1982 revised criteria for the classification of systemic lupus erythematosus. Arthritis Rheum. 25:1271-1277.

30. Ropes, M. W., G. A. Bennet, S. Caleb, R. Jacox, and R. A. Jessar. 1958. Revision of diagnostic criteria for rheumatoid arthritis. Bull. Rheum. Dis. 9:175-176.

31. Moutsopoulos, H. M., Th. M. Chused, and D. Z. Mann. 1980. Sjögren's syndrome (Sicca syndrome): current issues. Ann. Intern. Med. 92:212-226 